ISSN: $1130-3743$

\title{
PREJUICIOS DEL ALUMNADO DE SECUNDARIA DE GIPUZKOA ANTE LA INMIGRACIÓN ${ }^{1}$
}

\section{Secondary students' prejudices towards immigration}

\author{
Préjugés des étudiants de l'enseignement secondaire \\ sur l'immigration
}

Félix Etxeberría Balerdi, Hilario Murua Cartón, Elisabet Arrieta, Joxe GARMENDIA LARRAÑAGA y Juan ETXEBERRÍA Murgiondo

Universidad del País Vasco. Facultad de Ciencias de la Educación. Avenida de Tolosa, 70.20018 Donostia.Spain.Correo-e: fetxeberria@ehu.es; hilario.murua@ ehu.es; elisabet.arrieta@ebu.es; joxe.garmendia@ebu.es; juanito@ebu.es

Fecha de recepción: marzo de 2013

Fecha de aceptación: junio de 2013

Biblid [(1130-3743) 25, 2-2013, 155-187]

RESUMEN

Hacemos una recopilación de los cuestionarios y los catálogos más conocidos sobre los prejuicios que existen en la sociedad en materia de inmigración y elaboramos un nuevo cuestionario, con escalas positivas y negativas de prejuicios, para aplicarlo al alumnado de secundaria del País Vasco. Analizamos las respuestas de casi 1.500 alumnos y obtenemos los principales prejuicios que existen entre este alumnado. Después examinamos esos prejuicios más consolidados y establecemos

1. Este artículo es uno de los resultados del trabajo del Grupo de Investigación "Donostia Research on Education And Multilingualism" (DREAM), apoyado por la Universidad del País Vasco [GIU09/35], y el proyecto "La competencia plurilingüe en el contexto escolar" apoyado por el Ministerio español de Ciencia e Innovación [EDU2009-11601]. 
un contraste con datos científicos, informes, estudios, etc., que ponen en discusión la solidez de esos prejuicios. Como resultado de este trabajo, creemos que ponemos a disposición de los educadores, dentro y fuera del aula, las bases para elaborar estrategias y planes de intervención educativa con el alumnado de secundaria.

Palabras clave: prejuicios, inmigración, educación, actitudes, xenofobia, educación intercultural, educación secundaria.

\section{SUMMARY}

We carried out a review of the best-known questionnaires and catalogues on prejudices regarding immigration that exist in society and we drew up a new questionnaire, with positive and negative scales of prejudices, in order to apply them to secondary school students in the Basque Country. We analysed the responses of almost 1,500 students and thus obtained results for the main prejudices existing amongst the students. Subsequently we examined these, the most consolidated, prejudices and compared them with scientific data, reports and other research, and which have generated debate about these prejudices. As a result of this research, we believe that we have made available to educators, inside and outside the classroom, the basis for drawing up strategies and plans for educational intervention with secondary school students.

Key words: prejudices, immigration, education, attitudes, xenophobia, intercultural education, secondary education.

\section{SOMMAIRE}

Nous avons fait une collecte des questionnaires et des catalogues connus sur les préjugés qui existent dans la société en matière d'immigration. Nous avons aussi développé un nouveau questionnaire, avec des échelles positives et négatives des préjugés, pour demander à des élèves du secondaire dans le Pays Basque. Nous avons analysé les réponses de plus de 1.500 étudiants et nous avons réussi une liste des préjugés les plus puissants qui existent parmi ces étudiants. Après, nous avons analysé ces préjugés plus solides pour établir un contraste avec les données scientifiques, rapports, études, etc. qui remettent en question le bien-fondé de ces préjugés. Â la suite de ce travail, nous croyons que nous fournissons des éducateurs dedans et hors du centre scolaire, la base pour l'élaboration de stratégies d'intervention et d'éducation avec les élèves du secondaire.

Mots clés: préjugés, immigration, éducation, attitudes, xénophobie, éducation interculturelle, enseignement secondaire. 


\section{INTRODUCCIÓN}

\subsection{Prejuicios e inmigración}

Uno de los aspectos más importantes a la hora de valorar la relación de la población autóctona con la realidad de la inmigración es el tema de las actitudes que muestran los nativos ante las personas extranjeras. El estudio de las actitudes y de los prejuicios es clave a la hora de entender los comportamientos de las personas (Allport, 1962) y, al parecer, el prejuicio constituye un primer paso necesario para comprender a los otros y nos dan una primera idea del contacto que debemos seguir respecto a los desconocidos. Y, sin embargo, toda representación del prejuicio o del estereotipo es reduccionista, porque limita la complejidad de una persona a unas características que, la mayoría de las veces, no se corresponde con esa realidad concreta.

Podemos definir como estereotipo perjudicial:

Toda representación generalizante que sirve para asociar un estatus inferior a una persona o que le impide ser tratada conforme a su individualidad y juzgada según sus propios actos (Conseil de l'Europe, 2011a).

El problema de los prejuicios es que tienen una influencia negativa en la justificación de restricciones a los derechos, servicios o prestaciones para las personas inmigrantes. Cuando se afirma que "los inmigrantes abusan de los servicios sociales", en el fondo estamos diciendo que hay que tener cuidado y limitar su acceso al país y que si quieren entrar deben ser autónomos o reunir algunas condiciones. En realidad se está justificando que no todos los inmigrantes tienen derechos como los nativos (Conseil de l'Europe, 2011a) y toda una serie de argumentos que van en la línea de restringir las ayudas que pueden recibir los inmigrantes y dar prioridad a los nativos.

Aunque los prejuicios parecen tener una estructura unitaria, ya sabemos (Brown, 1995; Breckler, 1984; Pettigrew y Meertens, 1995) que esa unidad está compuesta de elementos cognitivos, afectivos, conductuales y sociales. La dimensión cognitiva de las actitudes está formada por las creencias, ideas y pensamientos. La cara afectiva de las actitudes la constituyen los sentimientos, estados de ánimo y emociones asociadas. El componente conductual está formado por las tendencias, disposiciones y conductas específicas. Además, la dimensión social está constituida por la familia, los compañeros, los medios de comunicación y el ambiente en general influyen en la creación y desarrollo de los prejuicios. Por lo tanto, los prejuicios son creencias y sentimientos que nos invitan a actuar en determinada dirección, conforme con el entorno y la influencia del ambiente.

En el caso de los prejuicios de tipo étnico, el componente cognitivo está formado por ideas, pensamientos y creencias que constituyen los estereotipos, generalmente cargados de una valoración negativa. Para Pettigrew y Meertens (1995) la dimensión afectiva o prejuicio se alimenta de sentimientos o emociones 
F. ETXEBERRÍA BALERDI, H. MURUA CARTÓN, ELISABET ARRIETA, J. GARMENDIA LARRAÑAGA Y J. ETXEBERRÍA MURGIONDO

PREJUICIOS DEL ALUMNADO DE SECUNDARIA DE GIPUZKOA ANTE LA INMIGRACIÓN

negativas, o ausencia de positivas, respecto a determinados colectivos. Diversos autores, entre los que destaca Duckitt (1992), señalan que la aparición de las conductas discriminatorias se inicia con la formación de los estereotipos, las creencias, que llevan a sentimientos negativos y finalmente a comportamientos discriminatorios.

\subsection{Escalas e instrumentos de medida sobre prejuicios e inmigración}

La medida de las actitudes y prejuicios hacia los colectivos inmigrantes ha sufrido una importante transformación en el tiempo, al constatarse que existe una clara contradicción entre las manifestaciones explícitas de las actitudes prejuiciosas, en aparente descenso, y los comportamientos racistas, siempre presentes. Esta situación ha llevado a algunos autores (Dovidio y Gaertner, 1986) a la sospecha de que ese cambio de actitudes respecto al racismo manifiesto tiene más de apariencia que de realidad. Da la impresión de que es una manera más correcta de expresarse, más aceptable socialmente, mientras que los prejuicios y comportamientos siguen manteniéndose bajo otras formas de expresión, de una manera más sutil. Según estos autores, los sentimientos negativos hacia los inmigrantes no se expresan a través del odio o comportamientos manifiestos, sino a través de otras expresiones más sutiles, como la incomodidad, descontento, inseguridad, sentimiento de amenaza, etc. Es lo que ha venido en llamarse racismo simbólico, moderno, sutil, aversivo, latente, etc., que tienen en común estar caracterizados por sentimientos y creencias discriminatorios con matices diferentes al racismo tradicional.

Para Wieviorka (1991), el fenómeno del racismo abarca un conjunto amplio de expresiones, dependiendo de las circunstancias históricas y sociales, que pueden tener mayor o menor intensidad, desde el prejuicio a la violencia, pasando por la segregación y discriminación. En realidad, el discurso racista parece hacerse más moderado, más correcto, pero en el fondo va evolucionando, adquiriendo distintas formas que cumplen con la misma función que realiza el discurso racista tradicional: justificar y reforzar las relaciones de poder y dominación que tienen unos grupos sobre otros. Ya Allport (1962) afirmaba que el prejuicio se disfraza de formas aceptables e indirectas, para evitar las consecuencias negativas del que mantiene una actitud explícita.

Por las razones antes indicadas, cuando se pregunta a los ciudadanos sobre determinadas actitudes respecto a los inmigrantes, los ítems de carácter racista tradicional tienden a ser respondidos de manera más moderada por ser socialmente más aceptados. Pero si los ítems se refieren a prácticas culturales, prestaciones sociales y otros aspectos más abstractos, las respuestas inciden más directamente en reflejar actitudes de rechazo o prejuicio sutil. En esta línea es en la que han trabajado McConahay, Hardee y Batts (1981) con su Escala de Racismo Moderno, y más recientemente Pettigrew y Meertens (1995) con las Escalas de Prejuicio Manifiesto y Prejuicio Sutil. En España, Rueda y Navas (1996) han realizado una adaptación de estas escalas al contexto español, con su instrumento denominado Escala Manifiesta y Escala Sutil. Estos autores utilizaron como grupo de investigación 
a estudiantes de secundaria y primeros cursos de universidad, y el colectivo objeto de prejuicio estaba constituido por gitanos, magrebíes y negros.

\subsection{Estudios sociológicos}

La presencia de los prejuicios en nuestra sociedad ha sido analizada de una manera continuada desde distintas entidades y puntos de vista. El Observatorio de Asuntos Sociales del País Vasco (Ikuspegi) realiza periódicamente estudios sobre las percepciones y actitudes hacia la inmigración extranjera (Ikuspegi, 2011). El Ararteko, o Defensor del Pueblo del País Vasco, ha realizado así mismo varios estudios en los que se recogen las actitudes de los escolares respecto a determinados colectivos de la sociedad (Ararteko, 2009). El Centro de Investigaciones Sociológicas (CIS, 2009) muestra también los resultados al nivel del Estado español. También desde la Unión Europea (Conseil de l'Europe, 2011) se ha tratado el tema de los prejuicios, analizando la situación en diversos países europeos.

Las principales conclusiones que se pueden extraer de estos estudios muestran que la existencia de prejuicios es un hecho consolidado en nuestra sociedad y que el paso de los años viene a certificar la consistencia de esas creencias y actitudes de la ciudadanía.

La consistencia de los prejuicios contrasta con la realidad de estudios e investigaciones en los que se analizan la situación y las perspectivas de futuro de nuestra sociedad en relación a la inmigración (Moreno y Bruquetas, 2011; Consejo Económico y Social Vasco, 2011; Pajares, 2010; Conseil de l'Europe, 2011). Estos trabajos ponen de manifiesto la falta de argumentos que fundamenten la existencia de esos prejuicios y destacan la menor utilización de los servicios sociales por parte de la población inmigrante y la dependencia que tiene nuestra sociedad respecto a ellos en una perspectiva corta y media.

\subsection{Iniciativas de prevención y formación}

Además de estos estudios, contamos también con otros trabajos realizados por diversas instituciones que han analizado el tema de los prejuicios desde una óptica pedagógica y han elaborado varios catálogos de los principales prejuicios o rumores para su utilización en la prevención y en la formación. Destacamos principalmente a la Cruz Roja (2012), el Ayuntamiento de Barcelona, el Gobierno Vasco (2012) y el Consejo de Europa (2011a).

Todos estos catálogos de prejuicios tienen una curiosa coincidencia en cuanto a su número, mayoritariamente 12 , y en cuanto a su contenido relativo a "nos están invadiendo, acaparan las ayudas sociales, aumentan la delincuencia, quitan el trabajo a los de aquí, etc.".

Esta unanimidad a la hora de realizar el listado de los principales prejuicios que existen en nuestra sociedad respecto a la inmigración nos da pie a plantearnos 
En la Secretaría de Teoría de la Educación. Revista Interuniversitaria se recibieron durante 2013 un total de 81 trabajos pertenecientes a 109 autores, con procedencia de instituciones científicas extranjeras en el quince por ciento de los casos. De los 81 trabajos recibidos 19 han sido publicados, 58 han sido rechazados y otros 4 están pendientes de publicación. La tasa de rechazo resultante es del 72\%.

El proceso de evaluación de los trabajos ha sido doblemente anónimo, con participación de 50 revisores externos que emitieron un total de 174 informes. El $25 \%$ de los revisores pertenece a instituciones científicas extranjeras.

Araújo, Alberto Filipe

Argos González, Javier

Asensio Aguilera, José María

Azevedo, María da Conceição

Aznar Minguet, Pilar

Bárcena Orbe, Fernando

Bezerra Barbosa, Fátima María

Boavida, João

Buxarrais Estrada, María Rosa

Colom Cañellas, Antoni Joan

Contini, Mariagrazzia

Domínguez Rodríguez, Emilia

Escámez Sánchez, Juan

Etxeberría Balerdi, Félix

Fermoshino, Dores

Fernández March, Amparo

García Aretio, Lorenzo

Gargallo López, Bernardo

Gennari, Mario

Gervilla Castillo, Enrique

Gil Cantero, Fernando

González Faraco, Juan Carlos

Hirsch Adler, Ana Cecilia

Jordán Sierra, José Antonio

Jover Olmeda, Gonzalo

Larrosa Bondía, Jorge

Martínez Martín, Miguel

Masschelein, Jan

Martínez Mut, Bernardo
Universidade do Minho

Universidad de Cantabria

Universidad Autónoma de Barcelona

Universidade de Trás-os-Montes e Alto

Douro

Universidad de Valencia

Universidad Complutense de Madrid

Universidade do Minho

Universidade de Coimbra

Universidad de Barcelona

Universidad de las Islas Baleares

Università di Bologna

Universidad de Extremadura

Universidad de Valencia

Universidad del País Vasco

Universidade de Coimbra

Universidad Politécnica de Valencia

Universidad Nacional de Educación a

Distancia

Universidad de Valencia

Università degli Estudi di Genova

Universidad de Granada

Universidad Complutense de Madrid

Universidad de Huelva

Universidad Nacional Autónoma de

México

Universidad de Barcelona

Universidad Complutense de Madrid

Universidad de Barcelona

Universidad de Barcelona

Katholieke Universiteit Leuven

Universidad Politécnica de Valencia 

PREJUICIOS DEL ALUMNADO DE SECUNDARIA DE GIPUZKOA ANTE LA INMIGRACIÓN

TABla 1. Participantes EN El ESTUdio

\begin{tabular}{|c|c|c|}
\hline CURSO & EDAD AÑOS & NÚMERO ALUMNOS \\
\hline ESO 1 & 12 & 268 \\
\hline ESO 2 & 13 & 248 \\
\hline ESO 3 & 14 & 267 \\
\hline ESO 4 & 15 & 198 \\
\hline BACHILLER 1 & 16 & 305 \\
\hline BACHILLER 2 & 17 & 207 \\
\hline Total & & 1.493 \\
\hline
\end{tabular}

De los 1.493 alumnos encuestados, el 52\% son chicas y el 48\% son chicos. Respecto al país de nacimiento, conforme a las respuestas del cuestionario, el 91,6\% ha nacido en el País Vasco (o en otra comunidad autónoma) y el 8,4\% ha nacido en el extranjero.

\subsection{Instrumentos}

Por nuestra parte, desde la Universidad del País Vasco, hemos realizado una adaptación de algunos de los instrumentos antes citados, teniendo en cuenta además los estudios sociológicos y los catálogos de prejuicios que distintas entidades, también señaladas más arriba, han ido elaborando con fines formativos. Fruto de este trabajo es el cuestionario que consta de 20 ítems, 10 en positivo y 10 en negativo, en donde se recogen algunos de los principales aspectos destacados en la bibliografía sobre el tema y en los informes y sondeos que se realizan periódicamente por parte de diversos agentes.

Uno de los aspectos que hemos querido resaltar en nuestro cuestionario de evaluación ha sido el contar con los datos referentes a actitudes tanto positivas como negativas, es decir, teniendo en cuenta los aspectos fuertes o constructivos de los encuestados, frente a los puntos más débiles o discriminatorios de los examinados. Un ejemplo de ítem positivo es "Las personas inmigrantes son trabajadoras", mientras que un ejemplo negativo está representado por "Los inmigrantes nos están invadiendo". Las dos escalas, positiva y negativa, pueden verse en la Tabla 2.

\subsection{Procedimiento}

Se presentó la encuesta a los sujetos en el marco de un estudio sobre las actitudes del alumnado respecto a los inmigrantes. Tras cumplimentar unos datos identificativos respecto a modelo lingüistico, sexo, nivel escolar y origen de nacimiento, valoraron los 10 ítems positivos y 10 ítems negativos en una escala de Likert que va de 1 a 10 puntos. El total de los ítems positivos suma 100 puntos y el de los negativos también es de 100 puntos. 

PREJUICIOS DEL ALUMNADO DE SECUNDARIA DE GIPUZKOA ANTE LA INMIGRACIÓN

\subsection{Análisis estadísticos}

El análisis de Fiabilidad realizado para las dos escalas, positiva y negativa, nos ofrece una Alpha de Crombach de 0,782 para la escala positiva y de 0,801 para la escala negativa. Se considera que a partir de valores superiores a 0,7 son suficientes para garantizar la fiabilidad de la escala. Por lo tanto, podemos afirmar que el instrumento es fiable.

\section{Resultados}

A continuación mostramos los valores obtenidos (máximo 10) en las dos escalas que se han medido en nuestro cuestionario sobre actitudes relacionadas con la inmigración.

\section{TABLA 2. ESCALAS POSITIVA Y NEGATIVA Y RESULTADOS}

\begin{tabular}{|c|c|}
\hline ESCALA POSITIVA & Media \\
\hline Los inmigrantes deben tener los mismos derechos que los demás & 7,22 \\
\hline Gracias a los inmigrantes conocemos otras culturas y lenguas & 6,54 \\
\hline Los inmigrantes hacen los trabajos que la gente de aquí no quiere & 6,29 \\
\hline Las personas inmigrantes son trabajadoras & 5,80 \\
\hline Las personas inmigrantes son gente buena & 5,63 \\
\hline Las personas inmigrantes hacen las cosas bien & 5,10 \\
\hline Con los inmigrantes aprendemos muchas cosas & 5,08 \\
\hline Las personas inmigrantes son amables & 5,05 \\
\hline Los inmigrantes nos ayudan para vivir mejor & 4,06 \\
\hline Los inmigrantes ayudan a mejorar la economía de Euskadi & 3,87 \\
\hline Media puntuaciones positivas & 6,5 \\
\hline ESCALA NEGATIVA & Media \\
\hline Los inmigrantes reciben más ayudas que los de aquí & 6,23 \\
\hline Los inmigrantes quitan el trabajo a los de aquí & 5,58 \\
\hline Los inmigrantes son más machistas que los de aquí & 5,36 \\
\hline Los inmigrantes nos están invadiendo & 5,12 \\
\hline Por culpa de los inmigrantes el euskara se perderá & 4,59 \\
\hline Los inmigrantes aumentan la delincuencia & 4,30 \\
\hline Los inmigrantes tienen menos formación y cultura que los de aquí & 4,17 \\
\hline Los inmigrantes bajan el nivel de nuestras escuelas & 4,03 \\
\hline Los inmigrantes traen enfermedades a Euskadi & 3,64 \\
\hline Los inmigrantes quieren imponernos su religión & 3,55 \\
\hline Media puntuaciones negativas & 4,5 \\
\hline
\end{tabular}

Examinando en la Tabla 2 los resultados obtenidos en el conjunto de la muestra examinada, la media de las puntuaciones positivas es de 6,5 , sobre 10 , muy por 
encima de la media de las puntuaciones negativas, 4,5. Esto puede indicar que las actitudes del alumnado examinado pesan más en sentido favorable a la convivencia y la aceptación de las personas inmigrantes. Puede indicar, en principio, una buena base para el trabajo preventivo y de preparación del alumnado.

El balance es muy positivo en referencia a la defensa de los derechos humanos para los inmigrantes. Esto puede dar un buen juego para su posterior utilización en la elaboración de programas educativos sobre el tratamiento de los prejuicios. También destaca la imagen que los encuestados tienen sobre los inmigrantes, como trabajadores, gente buena y que hacen los trabajos que la gente de aquí no quiere.

Junto al balance positivo conviven también actitudes negativas entre el alumnado, con lo que se confirma una de las características de este y otros estudios, es decir, la presencia de una doble actitud de los encuestados, una actitud dual que muestra muchos aspectos positivos, pero también comparte las actitudes y creencias negativas reflejadas en las encuestas y barómetros. Da la impresión de que vemos a los inmigrantes como personas con los mismos derechos humanos que los nativos, que ayudan y trabajan, pero al mismo tiempo los consideramos como invasores, abusando de las ayudas sociales, originando más delincuencia y quitando el trabajo a los de aquí. Esta aparente contradicción está muy generalizada en los estudios que conocemos.

\subsection{Las actitudes del alumnado según edad, sexo y procedencia}

3.1.1. Prejuicio y edad

FIgURA 1. PREJUICIO Y EDAD

PREJUICIOS. SUMA DE PUNTUACIONES POSITIVAS Y SUMA DE PUNTUACIONES NEGATIVAS SEGUN NIVEl $(\mathrm{N}=1.493)$

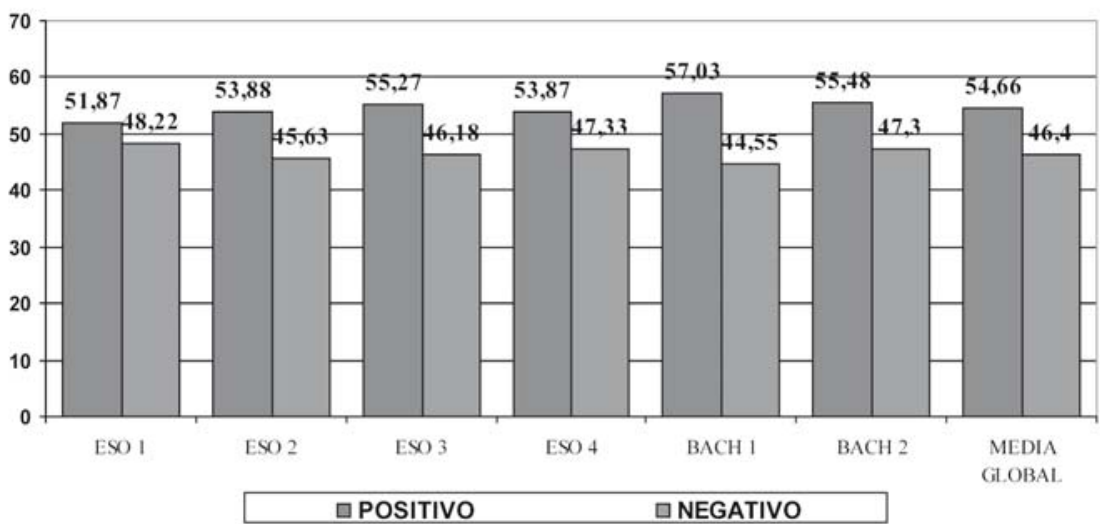


164 F. ETXEBERRÍA BALERDI, H. MURUA CARTÓN, ELISABET ARRIETA, J. GARMENDIA LARRAÑAGA Y J. ETXEBERRÍA MURGIONDO PREJUICIOS DEL ALUMNADO DE SECUNDARIA DE GIPUZKOA ANTE LA INMIGRACIÓN

En la Figura 1 pueden verse las puntuaciones totales, el resultado del sumatorio de los ítems positivos y negativos (máximo 100 puntos en cada una de las escalas). Las puntuaciones positivas y negativas se mantienen de modo similar en el nivel de ESO, Educación Secundaria Obligatoria (12-15 años). Tampoco sufren variaciones significativas las puntuaciones en el nivel de Bachillerato (16-17 años).

Figura 2. Prejuicios y etapas educativas
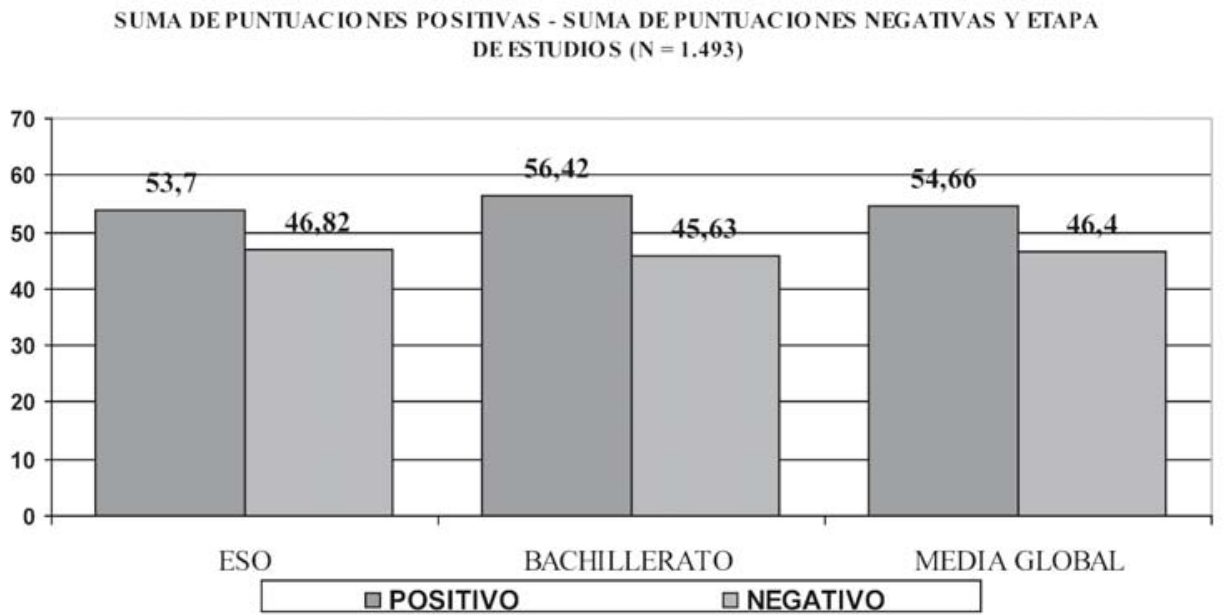

Por otra parte, si analizamos la Figura 2, comparando las puntuaciones totales entre cada una de las etapas (ESO y Bachillerato), podemos comprobar que en el nivel de Bachillerato (16-17 años) el total de los ítems positivos aumenta significativamente respecto a la etapa ESO (12-15 años), mientras que el total de los ítems negativos no varía de modo significativo al comparar el nivel de ESO con el Bachillerato. Las diferencias de las puntuaciones en las dos etapas sí son significativas en la escala positiva, pero no son significativas en la escala negativa.

\subsubsection{Prejuicio y sexo}

Respecto a la variable sexo (Figura 3), en nuestro estudio los chicos y chicas obtienen puntuaciones similares en relación al nivel de actitudes y prejuicios global. Se constata que, aunque haya pequeñas diferencias a favor de las chicas en la escala positiva y a favor de los chicos en la escala negativa, estas diferencias no son significativas. El diferencial positivo-negativo en los chicos es de 7,43 puntos, mientras que en el caso de las chicas es de 9,09 puntos. 
PREJUICIOS DEL ALUMNADO DE SECUNDARIA DE GIPUZKOA ANTE LA INMIGRACIÓN

Figura 3. Prejuicio y SEXO

PREJUICIOS. SUMA DE PUNTUACIONES POSITIVAS Y SUMA DE PUNTUACIONES NEGATIVAS SEGUN SEXO $(\mathrm{N}=1.493)$

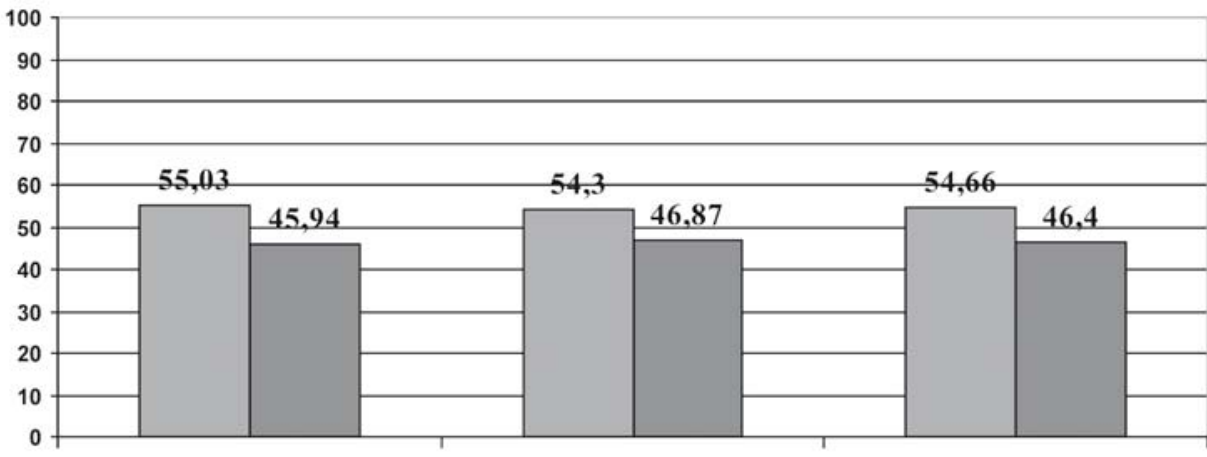

CHICA CHICO MEDIA GLOBAL

口POSITIVO 口NEGATIVO

En un análisis detallado solamente encontramos algunos ítems que muestran diferencias significativas entre los dos sexos. Comprobamos que las chicas puntúan más alto en el caso de tres ítems positivos: "Los inmigrantes son amables", "Con los inmigrantes aprendemos muchas cosas" $\mathrm{y}$ "Gracias a ellos conocemos otras culturas y lenguas". Los chicos, por su parte, puntúan más alto en tres ítems negativos: "Los inmigrantes aumentan la delincuencia", "Los inmigrantes bajan el nivel de nuestras escuelas" y "Los inmigrantes traen enfermedades a Euskadi".

\subsubsection{Prejuicio y lugar de nacimiento}

En nuestro estudio comparativo entre las puntuaciones en las escalas de las actitudes y prejuicios ante la inmigración, como era de suponer, se constatan diferencias muy significativas entre los valores obtenidos con los alumnos de origen extranjero y los alumnos nacidos en el País Vasco.

En la Figura 4 observamos que las puntuaciones en la escala positiva son significativamente más altas en el caso de los inmigrantes o nacidos en un país extranjero, mientras que las cifras en la escala negativa son significativamente más elevadas entre el alumnado autóctono o nacido en el País Vasco (o en otra comunidad autónoma). Los inmigrantes tienen una imagen más positiva de sí mismos y una menor autopercepción negativa, en comparación con los estudiantes nacidos en el País Vasco. El diferencial de puntuaciones positivo-negativo es en el caso de los autóctonos de 7 puntos, subiendo a 22,63 puntos entre el alumnado inmigrante. 
PREJUICIOS. PUNTUACIONES POSITIVAS Y NEGATIVAS SEGÚN ORIGEN $(N=1.493)$

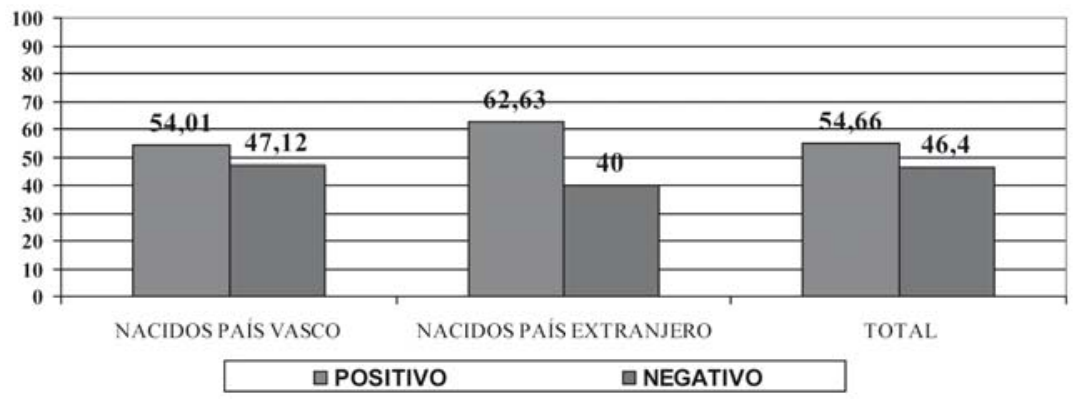

En un análisis más detallado de los distintos ítems que componen la escala positiva y negativa del cuestionario, observamos diferencias significativas en diversos aspectos. Como era de suponer, las personas nacidas en el extranjero tienen mayor nivel de valoración positiva hacia los inmigrantes, mientras que los nacidos en el País Vasco superan a los extranjeros en los ítems de carácter negativo.

Todos los ítems positivos tienen puntuaciones significativamente más elevadas por parte de los inmigrantes, excepto el ítem "Hacen los trabajos que la gente de aquí no quiere", en el que las diferencias no son significativas. La mayoría de los ítems negativos tienen puntuaciones significativamente más elevadas por parte de los autóctonos, excepto los siguientes, en los que las diferencias no son significativas: "Los inmigrantes aumentan la delincuencia", "Los inmigrantes tienen menos formación y cultura que los de aquí" y "Los inmigrantes son más machistas que los de aquí".

La Tabla 3 muestra los valores diferentes en cada ítem, según el país de nacimiento, y la significación de esas diferencias entre nativos e inmigrantes.

TABla 3. PRejuicios y ORIGEN DE NACIMIENTO

\begin{tabular}{|l|c|c|c|c|c|}
\hline \multicolumn{1}{|c|}{ ÍTEMS POSITIVOS } & $\begin{array}{c}\text { PAÍS DE } \\
\text { NACIMIENTO }\end{array}$ & $\mathrm{N}$ & MEDIA & $\begin{array}{c}\text { DESV. } \\
\text { TÍP. }\end{array}$ & SIGNI \\
\hline Los inmigrantes nos ayudan para vivir mejor & PAÍS VASCO & 1.298 & 3,95 & 2,018 &, 000 \\
\hline & EXTRANJERO & 118 & 5,31 & 2,584 & \\
\hline Las personas inmigrantes son amables & PAÍS VASCO & 1289 & 4,95 & 1,823 &, 000 \\
\hline & EXTRANJERO & 116 & 6,33 & 2,253 & \\
\hline Con los inmigrantes aprendemos muchas cosas & PAÍS VASCO & 1.302 & 4,98 & 2,450 &, 000 \\
\hline & EXTRANJERO & 117 & 6,33 & 2,659 & \\
\hline Las personas inmigrantes son trabajadoras & PAÍS VASCO & 1.299 & 5,71 & 2,064 &, 000 \\
\hline
\end{tabular}


F. ETXEBERRÍA BALERDI, H. MURUA CARTÓN, ELISABET ARRIETA, J. GARMENDIA LARRAÑAGA Y J. ETXEBERRÍA MURGIONDO PREJUICIOS DEL ALUMNADO DE SECUNDARIA DE GIPUZKOA ANTE LA INMIGRACIÓN

\begin{tabular}{|l|c|c|c|c|c|}
\hline & EXTRANJERO & 118 & 6,62 & 2,360 & \\
\hline Deben tener los mismos derechos que los demás & PAÍS VASCO & 1.285 & 7,14 & 2,914 &, 000 \\
\hline & EXTRANJERO & 119 & 8,16 & 2,777 & \\
\hline Las personas inmigrantes hacen las cosas bien & PAÍS VASCO & 1.288 & 5,06 & 1,711 &, 002 \\
\hline & EXTRANJERO & 115 & 5,57 & 1,897 & \\
\hline $\begin{array}{l}\text { Gracias a ellos conocemos } \\
\text { otras culturas y lenguas }\end{array}$ & PAÍS VASCO & 1.299 & 6,46 & 2,631 &, 000 \\
\hline & EXTRANJERO & 118 & 7,53 & 2,646 & \\
\hline Las personas inmigrantes son gente buena & PAÍS VASCO & 1.295 & 5,56 & 1,760 &, 000 \\
\hline & EXTRANJERO & 113 & 6,39 & 2,258 & \\
\hline $\begin{array}{l}\text { Hacen los trabajos que la gente } \\
\text { de aquí no quiere }\end{array}$ & PAÍS VASCO & 1.302 & 6,30 & 2,639 &, 274 \\
\hline & EXTRANJERO & 116 & 6,02 & 2,892 & \\
\hline Ayudan a mejorar la economía de Euskadi & PAÍS VASCO & 1.291 & 3,78 & 2,086 &, 000 \\
\hline
\end{tabular}

\begin{tabular}{|c|c|c|c|c|c|}
\hline ÍTEMS NEGATIVOS & $\begin{array}{c}\text { PAÍS DE } \\
\text { NACIMIENTO }\end{array}$ & $\mathrm{N}$ & MEDIA & $\begin{array}{l}\text { DesV. } \\
\text { TíP. }\end{array}$ & SIGNI \\
\hline \multirow[t]{2}{*}{ Los inmigrantes nos están invadiendo } & PAÍS VASCO & 1.291 & 5,22 & 2,778 & ,002 \\
\hline & EXTRANJERO & 118 & 4,38 & 2,840 & \\
\hline \multirow[t]{2}{*}{ Reciben más ayudas que los de aquí } & PAÍS VASCO & 1.296 & 6,38 & 2,733 &, 000 \\
\hline & EXTRANJERO & 118 & 4,99 & 2,842 & \\
\hline \multirow[t]{2}{*}{$\begin{array}{l}\text { Por culpa de los inmigrantes } \\
\text { el euskara se perderá }\end{array}$} & PAÍS VASCO & 1.296 & 4,70 & 2,835 &, 000 \\
\hline & EXTRANJERO & 120 & 3,28 & 2,644 & \\
\hline \multirow[t]{2}{*}{ Los inmigrantes quieren imponernos su religión } & PAÍS VASCO & 1.287 & 3,62 & 2,612 &, 000 \\
\hline & EXTRANJERO & 117 & 2,71 & 2,446 & \\
\hline \multirow[t]{2}{*}{ Los inmigrantes aumentan la delincuencia } & PAÍS VASCO & 1.297 & 4,32 & 2,335 & ,739 \\
\hline & EXTRANJERO & 117 & 4,25 & 2,636 & \\
\hline \multirow[t]{2}{*}{ Los inmigrantes traen enfermedades a Euskadi } & PAÍS VASCO & 1.294 & 3,71 & 2,465 &, 000 \\
\hline & EXTRANJERO & 120 & 2,86 & 2,488 & \\
\hline \multirow[t]{2}{*}{ Los inmigrantes quitan el trabajo a los de aquí } & PAÍS VASCO & 1.295 & 5,70 & 2,815 &, 000 \\
\hline & EXTRANJERO & 118 & 4,28 & 3,063 & \\
\hline \multirow[t]{2}{*}{$\begin{array}{l}\text { Tienen menos formación y } \\
\text { cultura que los de aquí }\end{array}$} & PAÍS VASCO & 1.280 & 4,16 & 2,446 & 487 \\
\hline & EXTRANJERO & 116 & 4,33 & 2,728 & \\
\hline \multirow[t]{2}{*}{$\begin{array}{l}\text { Los inmigrantes bajan el nivel } \\
\text { de nuestras escuelas }\end{array}$} & PAÍS VASCO & 1.295 & 4,07 & 2,599 & ,022 \\
\hline & EXTRANJERO & 118 & 3,49 & 2,760 & \\
\hline \multirow[t]{2}{*}{$\begin{array}{l}\text { Los inmigrantes son más } \\
\text { machistas que los de aquí }\end{array}$} & PAÍS VASCO & 1.289 & 5,44 & 2,726 & ,063 \\
\hline & EXTRANJERO & 114 & 4,95 & 2,859 & \\
\hline
\end{tabular}


F. ETXEBERRía BALERDI, H. MURUA CARTÓN, ELISABET ARRIETA, J. GARMENDIA LARRAÑAGA Y J. ETXEBERRÍA MURGIONDO PREJUICIOS DEL ALUMNADO DE SECUNDARIA DE GIPUZKOA ANTE LA INMIGRACIÓN

\section{DISCUSIÓN}

\subsection{Objetivos de la investigación}

En relación a los objetivos de esta investigación, a lo largo de este trabajo hemos demostrado que en el seno del alumnado de ESO y de Bachillerato de Gipuzkoa existen arraigadas una serie de actitudes positivas y negativas con respecto a la presencia de personas inmigrantes en la comunidad. Hemos mostrado también cuáles son las principales actitudes de carácter positivo y de carácter negativo, con lo cual disponemos de la información necesaria para elaborar planes y programas educativos en relación a los prejuicios hacia la inmigración.

Las escasas diferencias encontradas en razón de la edad y del sexo del alumnado nos permiten interpretar que los prejuicios están sólidamente arraigados entre los jóvenes, al igual que en el resto de la ciudadanía, o que no existen planes específicos en educación para combatir estas actitudes. Puede que ocurran ambas cosas a la vez.

\subsection{Prejuicios y edad}

Las puntuaciones del alumnado de Educación Secundaria Obligatoria (ESO) son bastante similares desde 1. hasta 4.ำ sin que apenas exista variación entre los 12 y los 15 años. Tampoco son significativas si las comparamos con el alumnado de Bachillerato.

Comparando las puntuaciones totales entre cada una de las etapas (ESO y Bachillerato), podemos comprobar que en el nivel de Bachillerato (16-17 años) el total de los ítems positivos aumenta significativamente respecto a la etapa ESO (12-15 años), mientras que el total de los ítems negativos no varía de modo significativo al comparar el nivel de ESO con el Bachillerato. Es decir, al pasar de ESO a Bachillerato parecen mantenerse solidamente los prejuicios negativos, pero aumentan las actitudes positivas hacia la inmigración. También puede indicar que, conforme avanza la edad, los jóvenes aprenden a responder más correctamente a determinadas preguntas.

En relación a la variable edad, si comparamos los resultados obtenidos en otras investigaciones en las que se han analizado las respuestas del alumnado de ESO y Bachillerato, podemos comprobar que en el estudio de FernándezCastillo y Fernández (2006) también se obtienen resultados similares. Sin embargo, se encuentran diferencias significativas dentro del bloque de alumnos de ESO analizados por García, Navas, Cuadrado y Molero (2003), para quienes la Escala de Racismo Moderno arroja puntuaciones más altas para los alumnos de 2. de ESO, siendo las más bajas las de los alumnos de 4. de ESO (15 años). Fernández-Castillo y Fernández (2006) también encontraron diferencias significativas en la escala de prejuicios entre los alumnos de ESO (12 a 14 años), ratificando la disminución del racismo manifiesto conforme aumenta la edad infantil. Por su parte, León, Ricardo y Gómez (2007), en una investigación realizada con alumnado de Magisterio, no 
obtuvieron diferencias significativas en razón de la edad ni del sexo. Eran sujetos mayores de 18 años. Sí vieron diferencias significativas en razón de la edad Retortillo y Rodríguez (2008), quienes comparando las puntuaciones de estudiantes de ESO/ Bachillerato y estudiantes universitarios observaron mayor grado de racismo sutil por parte de los alumnos de Secundaria. Igualmente, García, Navas, Cuadrado y Morelo (2003), en una investigación con sujetos de 2.ำ a $4 .^{\circ}$ de ESO, observaron que el grado de Racismo Moderno desciende conforme los participantes se hacen mayores y avanzan de curso.

Teniendo en cuenta estas investigaciones llevadas a cabo en España, aunque no hay unanimidad, la conclusión que parece desprenderse de estas investigaciones es que las actitudes de prejuicio o de racismo definen una curva que tiene su máximo en los últimos años de primaria y primeros cursos de ESO y luego va descendiendo conforme aumenta la edad.

En nuestra investigación, llevada a cabo en el País Vasco, no se observan diferencias significativas cuando comparamos las puntuaciones globales en positivo o en negativo (diez ítems en cada uno) de los cuatro niveles de la Educación Secundaria Obligatoria (12-15 años), pero sí observamos diferencias significativas en la escala positiva cuando comparamos la etapa ESO (12 a 15 años) con el Bachillerato (16 años en adelante). Tampoco se encuentran diferencias significativas cuando analizamos con detalle los distintos ítems que componen cada una de las escalas negativa y positiva del cuestionario.

Respecto a las discrepancias entre nuestros resultados y los obtenidos en otras investigaciones hemos de decir que tampoco son unánimes las conclusiones en dichos estudios. Además, en nuestro caso, hay que tener en cuenta que el instrumento empleado no es el mismo.

\subsection{Prejuicios y sexo}

En relación a la variable sexo, no hay diferencias significativas entre chicos y chicas si tenemos en cuenta el total de ítems positivos y el total de ítems negativos. Sí aparecen diferencias significativas en tres ítems positivos, con puntuaciones más altas para las chicas, y en tres ítems negativos, con puntuaciones más altas para los chicos.

En las investigaciones de Fernández-Castillo y Fernández (2006) y García, Navas, Cuadrado y Molero (2003), se comprueba la existencia de puntuaciones más altas en la escala de Racismo en el caso de los chicos, significativamente por encima de las puntuaciones de las chicas. Sin embargo en León, Ricardo y Gómez (2007) se muestra que las puntuaciones entre chicos y chicas no difieren significativamente. García, Navas, Cuadrado y Molero (2003), por su parte, constatan alguna diferencia en relación al sexo, siendo ligeramente superiores las puntuaciones de los chicos en la Escala de Racismo Moderno.

Teniendo en cuenta estas investigaciones llevadas a cabo en España, la conclusión en relación a la variable sexo, aunque no hay unanimidad, parece 
indicar que las actitudes de prejuicio de racismo son ligeramente superiores en el caso de los chicos, aunque las diferencias no son muy significativas.

En nuestra investigación, llevada a cabo en el País Vasco, no se observan diferencias significativas entre las puntuaciones de los chicos y las chicas.

Al igual que con la variable edad, en el caso de la variable sexo, las discrepancias entre nuestros resultados y los obtenidos en otras investigaciones hemos de decir que tampoco son unánimes las conclusiones en dichos estudios. Por otra parte, hay que tener en cuenta que el instrumento empleado no es el mismo.

\subsection{Prejuicios y origen}

Como era de suponer, existen diferencias significativas entre las afirmaciones del alumnado inmigrante y el alumnado autóctono. Si tenemos en cuenta el sumatorio total de los ítems negativos y positivos, esas diferencias indican que el alumnado inmigrante puntúa más alto en los aspectos positivos y más bajo en los ítems negativos. También son significativas las diferencias en la mayoría de los items por separado.

Otros autores han analizado el tema de los prejuicios desde el punto de vista de las personas inmigrantes (Navas, García, Rojas, Pumares y Cuadrado, 2006) han encontrando una mayor relación entre el prejuicio y la actitud de aculturación general entre autóctonos que entre inmigrantes. Es un interesante punto de vista que en nuestro caso no hemos analizado, pero que debiera tenerse en cuenta para hacerse una idea más completa de la relación entre alumnado autóctono e inmigrante y las consecuencias pedagógicas que de este hecho se derivan.

\subsection{Diferencias entre el bloque positivo y el negativo}

Comprobamos que, en todos los niveles, son más altas las puntuaciones en el bloque positivo que en el negativo. Las diferencias entre ambos bloques son más destacadas en los cursos superiores. Este dato permite albergar una buena dosis de esperanza a la hora de hacer planes y propuestas educativas, puesto que podremos contar con el concurso de una buena actitud de base hacia las personas inmigrantes por parte del alumnado que hemos examinado.

Aunque los datos de las actitudes negativas son inferiores en puntuación a las actitudes positivas, la existencia clara de varios aspectos negativos indicadores de prejuicio nos hace presumir que el cuestionario utilizado detecta bien los principales prejuicios que se repiten una y otra vez en todos los estudios e investigaciones que se han llevado a cabo, hasta el punto de constituir una especie de catálogo de tópicos sobre los prejuicios ante la inmigración. 

PREJUICIOS DEL ALUMNADO DE SECUNDARIA DE GIPUZKOA ANTE LA INMIGRACIÓN

\subsection{Limitaciones de este estudio}

Probablemente, los resultados de esta investigación reflejan una actitud "correcta" ante determinados problemas relacionados con la inmigración, a tenor de las expresiones abiertamente xenófobas que conocemos en la sociedad. Es de temer que las verdaderas actitudes y comportamientos prejuiciosos sean más intensos que los niveles que se reflejan en este estudio.

Fernández-Castillo y Fernández (2006) también manifiestan esta sospecha cuando afirman que "posiblemenete los sujetos tiendan a reprimir sus pensamientos racistas cuando han de expresarlos abiertamente... pero que por el contrario sí tiendan a mostrarse más prejuiciosos cuando han de expresar esa opinión de forma más suave, encubierta o sutil".

Por otra parte, el hecho de que el cuestionario pregunte únicamente sobre las actitudes hacia las personas inmigrantes deja en la sombra la realidad de las actitudes de los inmigrantes hacia los autóctonos, con lo cual no disponemos de una información valiosa a la hora de elaborar planes y programas educativos.

En nuestro estudio no se ha tenido en cuenta la diferente procedencia de los inmigrantes y probablemente la actitud hacia los mismos por parte del alumnado autóctono varíe sustancialmente si se trata de magrebíes, latinos o rumanos.

Finalmente, no podemos dejar de lado el hecho de que en la escala positiva pueden aparecer también varias respuestas favorables o actitudes entusiastas de apoyo a los inmigrantes que, probablemente, tampoco tienen base en los hechos reales y que pueden constituir otro ejemplo de prejuicio, en este caso de tipo positivo.

\section{BASES PARA UNA PROPUESTA EDUCATIVA EN ENSEÑANZA SECUNDARIA}

\subsection{Principales prejuicios sobre inmigración en secundaria}

Con todo lo mostrado hasta ahora disponemos de la encuesta con los resultados globales para una muestra del alumnado de secundaria (12-17 años) de Gipuzkoa. A partir de estos datos podemos saber cuáles son los principales prejuicios y su grado de arraigo en las actitudes de estos adolescentes.

Ya hemos dicho al comienzo de este artículo que los prejuicios parecen tener una estructura unitaria, y sabemos (Brown, 1995; Breckler, 1984; Pettigrew y Meertens, 1995) que esa unidad está compuesta de elementos cognitivos, afectivos, conductuales y sociales y que, por lo tanto, los prejuicios son creencias y sentimientos que nos invitan a actuar en determinada dirección, conforme con el entorno y la influencia del ambiente. 


\subsection{Un enfoque múltiple}

La mayoría de las propuestas de intervención que hemos citado al inicio de este artículo (Cruz Roja, Ayuntamiento de Barcelona, Gobierno Vasco, Consejo de Europa) tienen que ver con argumentos de tipo cognitivo. Por nuestra parte, teniendo en cuenta los cuatro componentes de los prejuicios que hemos indicado (cognitivo, emocional, conductual y social), hacemos una propuesta pedagógica que incida en esas cuatro direcciones:

- Perspectiva cognitiva. Muchos de los prejuicios se basan en datos erróneos o generalizaciones que no tienen justificación real. Es por ello por lo que hay que argumentar con datos contrastados e informaciones veraces para combatir las ideas prejuiciosas: datos, gráficos, textos, estadísticas, informes, estudios, etc.

- Perspectiva emocional. Los prejuicios se instalan también y se consolidan a través de mecanismos emocionales, de simpatía u odio hacia los demás, de humor, ironía, chistes, etc. Si queremos combatir los prejuicios, tendremos que intervenir también en este terreno emocional, ofreciendo otros canales, como el humor y la aproximación socioafectiva, promoviendo contactos positivos con personas inmigrantes.

- Perspectiva mediática. Una de las principales fuentes de creación y consolidación de los prejuicios se encuentra en los medios de comunicación, que tienen un gran peso a la hora de formar opiniones y generalmente hacen un tratamiento alarmista y negativo en torno a la inmigración. Hay que utilizar los medios de comunicación, cuanto sea posible, para contrarrestar la enorme influencia de la prensa y la TV (recortes de prensa, fotos, videoclips, programas de TV, etc.).

- Perspectiva participativa. El diálogo entre iguales es uno de los principales cauces de socialización. Lo que se dice en el grupo y la manera en que se dice influyen en la formación de los individuos. Por ello es importante impulsar el debate de ideas, hechos y argumentos para llegar a profundizar con espíritu autocrítico el tema de los prejuicios y llegar a despertar los comportamientos prosociales.

\subsection{Una secuencia educativa completa}

Con el fin de organizar una secuencia educativa completa, desde la identificación de los prejuicios hasta la implicación en actividades prosociales de los alumnos, el plan de intervención debiera contar con unos pasos fundamentales: 
a) Sensibilización ante los prejuicios

Nosotros también fuimos y somos emigrantes. Mostrar que históricamente también los vascos han sido emigrantes y en cierta medida vuelven a serlo con motivo de la crisis económica.

Identificar los prejuicios y estereotipos que existen entre los autóctonos, a distintos niveles.

Identificar los estereotipos y prejuicios sobre los inmigrantes. Elaborar un catálogo con los principales tópicos sobre los inmigrantes.

El peligro de las generalizaciones. Impulsar la reflexión sobre los riesgos de generalizar determinadas afirmaciones que se hacen sobre los autóctonos y sobre los inmigrantes.

¿Cómo se transmiten los prejuicios? Intentar descifrar de qué manera se llegan a pensar determinadas cosas que no se corresponden con la realidad. Especial mención a los medios de comunicación, la familia, los iguales, la calle, etc.

\section{b) Combatir los prejuicios}

Reflexionar sobre la importancia de la defensa de los derechos humanos por encima de cualquier origen de nacimiento.

Contrarrestar los prejuicios desde la múltiple perspectiva: cognitiva, mediática, emocional y participativa. Aportar datos, recursos audiovisuales, contacto y humor, además de impulsar actividades de grupo.

Como último paso en el programa de intervención, proponer iniciativas y actividades que permitan dar el paso hacia comportamientos o compromisos prosociales.

Evaluar los cambios de actitudes y conductas para poder realimentar el plan de actuación.

\section{DisCuSiÓN DE LOS PRINCIPALES ÍTEMS EN LA ESCALA NEGATIVA}

Dentro de la escala negativa, hemos seleccionado los seis principales ítems con carácter negativo. En la Tabla 4, además de las puntuaciones medias, ofrecemos también el grado de significación conforme a las variables independientes edad, sexo y lugar de origen. Tal y como vemos en la Tabla 4, únicamente existe diferencia significativa entre los chicos y chicas en el ítem sobre la delincuencia. Respecto al lugar de origen, observamos diferencias significativas en los ítems relativos a "reciben más ayudas", "quitan el trabajo", "nos están invadiendo" y "el euskara se perderá». La variable edad no proporciona diferencias significativas en ninguno de los seis principales ítems analizados. 
174 F. ETXEBERRÍA BALERDI, H. MURUA CARTÓN, ELISABET ARRIETA, J. GARMENDIA LARRAÑAGA Y J. ETXEBERRÍA MURGIONDO PREJUICIOS DEL ALUMNADO DE SECUNDARIA DE GIPUZKOA ANTE LA INMIGRACIÓN

TABla 4. PRINCIPALES ÍTEMS EN La ESCALA NEGATIVA

\begin{tabular}{|l|c|c|c|c|}
\hline \multirow{2}{*}{ PRINCIPALES ÍteMS DE LA ESCALA NEGATIVA } & \multirow{2}{*}{$\mathrm{X}$} & \multicolumn{2}{c|}{ SIGNIFICACIÓN SEGÚN } \\
\cline { 5 - 5 } & & EDAD & SEXO & ORIGEN \\
\hline Los inmigrantes reciben más ayudas que los de aquí & 6,23 & & & sí \\
\hline Los inmigrantes quitan el trabajo a los de aquí & 5,58 & & & sí \\
\hline Los inmigrantes son más machistas que los de aquí & 5,36 & & & \\
\hline Los inmigrantes nos están invadiendo & 5,12 & & & sí \\
\hline Por culpa de los inmigrantes el euskara se perderá & 4,59 & & & sí \\
\hline Los inmigrantes aumentan la delincuencia & 4,30 & & sí & \\
\hline
\end{tabular}

\section{1. "Los inmigrantes reciben más ayudas que los de aquí"}

\subsection{1. ¿Qué dice nuestro trabajo?}

En nuestro estudio, este ítem ha resultado con una puntuación general de 6,23 , la máxima de toda la escala de prejuicios. Las puntuaciones de los alumnos de ESO son ligeramente más elevadas que las de los alumnos de ciclos superiores, Bachillerato y ciclo superior. No hemos encontrado diferencias significativas en razón del sexo y del lugar de origen de los encuestados.

\subsubsection{Otros estudios e informes}

En el estudio realizado por Ikuspegiak (2011b), se constata que el 64,2\% de las personas encuestadas en Euskadi consideran que las personas inmigrantes se benefician excesivamente del sistema de protección social. Un 44,6\% considera que los extranjeros pagan menos impuestos de lo que luego reciben.

Según el CIS (2009), un 58,7\% de los encuestados opina que las personas inmigrantes reciben del Estado más o mucho más de lo que aportan.

Según el Informe del Consejo de Europa (Conseil de l'Europe, 2011a) esta creencia está muy extendida en la opinión pública y numerosos sondeos parecen confirmarlo. Este discurso sirve esencialmente para justificar la exclusión de las personas de origen extranjero respecto a los derechos sociales, o a imponerles un acceso restrictivo, dando prioridad a los nacionales, bajo el lema "primero los de casa".

Podemos afirmar que, en general, casi dos de cada tres personas consideran que los inmigrantes se benefician excesivamente de las ayudas sociales.

\subsubsection{La realidad de los hechos}

Según el estudio realizado para la Caixa, por Moreno y Bruquetas (2011), el número y porcentaje de usuarios de los servicios sociales de origen extranjero rondaba el 13,69\%, similar a su peso relativo en el conjunto de la población española. 
En el informe realizado por el Observatorio Vasco de la Vivienda (2012) se muestra que las personas adjudicatarias de vivienda protegida en Euskadi se corresponden con un 93\% de nacionalidad española y con un 7\% de nacionalidad extranjera, es decir, la proporción que tiene cada uno de los dos colectivos en la sociedad. Por lo tanto, no parece haber ningún trato de ventaja para las personas inmigrantes.

Según el Gobierno Vasco (2008), el gasto público sanitario realizado por los extranjeros fue en 2008 del 2,5\%, cuando su peso demográfico en Euskadi era del 5,4\%. En ese mismo informe se constata que en 2006 el gasto público de los inmigrantes era del 4\%, porcentaje similar al de la población extranjera en ese año en Euskadi. En dicho informe se muestra también que cada inmigrante aportó a la hacienda vasca aproximadamente 1.000 euros más que cada nativo en cargas fiscales.

El Estudio sobre las mujeres inmigrantes extranjeras en Euskadi, realizado por Emakunde (2012), indica que "las aportaciones fiscales de las mujeres extranjeras en la CAE, estimadas en 224,1 millones de euros, es muy superior a los ingresos que perciben por rentas no laborales, como ayudas sociales o prestaciones de desempleo, que alcanzan en 2010 los 142,3 millones de euros".

El informe del Consejo de Europa (Conseil de l'Europe, 2011a) concluye que dos inmigrantes en edad de trabajar cotizan como los nacionales y sin embargo cuando se jubilan no reciben por lo general todo lo que han cotizado. En todo caso pagan más impuestos que lo que luego obtienen como prestaciones". Por poner un ejemplo, en el tema de la salud "tienen más difícil acceso, por razones de edad y de constitución, por razones de barreras legales y administrativas a los servicios".

Por otra parte, según la Red ISIR Inmigración y Salud (2010) los inmigrantes acuden con menor frecuencia a los servicios de salud, consumen menos fármacos y realizan menos visitas al médico que los autóctonos.

Esta situación por la que las personas extranjeras utilizan en menor medida los servicios de salud puede tener relación con el hecho de que la población inmigrante es más joven que la autóctona, y también con la situación de desconocimiento del funcionamiento de los servicios y la situación laboral más precaria que impide dejar el trabajo para acudir al médico.

\subsubsection{Discusión}

A pesar de la consistencia de este prejuicio, la creencia de que la población extranjera recibe más ayuda que la autóctona no se corresponde con la realidad; es una percepción errónea a la hora de analizar el uso de los servicios sociales por parte de los dos colectivos.

Los datos demuestran lo contrario, y ello es debido a que, entre otras razones, la población extranjera está en la franja de edad de 25 a 44 años mayoritariamente. 
Es decir, la edad de trabajar y de gozar de buena salud, con menos necesidades sanitarias.

Incluso podríamos reducir el peso de las prestaciones sanitarias a los inmigrantes descontando la parte de personas extranjeras que como turistas visitan anualmente España, cantidad que ronda la cifra de 57 millones, y que en alguna medida también utilizan los servicios de salud.

Será necesario, por tanto, trabajar en las aulas para concienciar a los adolescentes y jóvenes sobre la realidad de la situación de la inmigración y la falta de fundamento de los argumentos que defienden el supuesto abuso por parte de los inmigrantes de los servicios y las ayudas sociales.

\section{2. "Los inmigrantes quitan el trabajo a los de aqui"}

\subsection{1. ¿Qué dice nuestro trabajo?}

En nuestro estudio, este ítem ha resultado con una puntuación general de 5,58 en la escala de 1 a 10. Las puntuaciones de los alumnos de ESO son más elevadas que las de los alumnos de ciclos superiores, Bachillerato y ciclo superior. Por su parte, los chicos y las chicas puntúan casi en la misma medida en esta pregunta. Si hacemos caso al país de origen, los nacidos en EH puntúan significativamente más alto que los nacidos en el extranjero.

\subsubsection{Otros estudios e informes}

En el estudio realizado por Ikuspegiak (2011b), se constata que las personas encuestadas en Euskadi consideran en un 55\% que la presencia de personas inmigrantes aumenta el paro en Euskadi. Sin embargo, ese mismo estudio destaca que un $47,5 \%$ de los entrevistados opinan que los sueldos bajan como consecuencia de la llegada de personas que vienen a vivir y trabajar y un 70,5\% piensa que ello perjudica más a los pobres que a los ricos.

Es importante señalar que en el informe del Observatorio Vasco de la Inmigración (Ikuspegi) se concluye que un 43\% de los participantes en la encuesta cree que necesitamos personas inmigrantes para trabajar en algunos sectores de nuestra economía y un 40\% manifiesta que los inmigrantes ocupan puestos de trabajo que la población autóctona no quiere. Esta visión dual de la inmigración se refleja también en otros estudios e investigaciones.

Según el cis (2009), un 55,4\% de los encuestados responden que están muy de acuerdo o más bien de acuerdo con la afirmación de que "los inmigrantes quitan puestos de trabajo a los españoles". Al mismo tiempo, un 78\% consideran que "los inmigrantes desempeñan trabajos que los españoles no quieren hacer».

Siguiendo el informe del Consejo de Europa (Conseil de l'Europe, 2011a), "se han realizado un gran número de estudios sobre este asunto en Europa y sin embargo los efectos de la inmigración sobre las oportunidades de empleo de los 
trabajadores autóctonos son muy reducidos y se hacen sentir únicamente en ciertos sectores, llegando a la conclusión de que los flujos migratorios no tienen ningún impacto sobre la tasa de paro de la población autóctona». Este informe señala que, en el caso de España, «los inmigrantes ocupan empleos poco o nada cualificados y por tanto apenas están en competencia con los trabajadores autóctonos".

El informe de Emakunde (2012) indica que cuatro de cada diez trabajadoras extranjeras están ocupadas en el servicio doméstico y 3,5 de cada 10 están ocupadas en el comercio y hostelería. "Se trata de dos sectores intensivos de mano de obra, con salarios relativamente bajos, que ha permitido obtener tiempo de trabajo mercantil a muchas mujeres vascas".

Este es el prejuicio que tiene una perspectiva doble o que los encuestados manifiestan una dualidad de opinión. Por un lado, opinan que los inmigrantes realizan trabajos que los españoles no quieren, pero por otro lado afirman que los inmigrantes quitan trabajo a los españoles.

\subsubsection{La realidad de los hechos}

El Consejo Económico y Social Vasco, en su informe de 2011, a la hora de contrarrestar el impacto del envejecimiento en el descenso de la población activa, recomienda aumentar la tasa de empleo en general, y entre otras medidas la de apostar por la integración laboral de los inmigrantes "que representa un capital humano de gran valor" (p. 156).

Por su parte, el Ministerio de Trabajo e Inmigración (Pajares, 2010), en su informe titulado Inmigración y mercado de trabajo. Informe 2010, concluye que los extranjeros sufren más desempleo y pierden más ocupación que los españoles. Al mismo tiempo, se indica que los extranjeros siguen concentrados en las categorías más bajas de menor cualificación y que los extranjeros no están sustituyendo a los trabajadores españoles en el mercado de trabajo.

\subsubsection{Discusión}

Es necesario plantear esta dualidad ante los adolescentes y jóvenes para hacer ver la complejidad de la situación económica y la doble cara con la que juzgamos a los inmigrantes. Son necesarios, pero les hacemos culpables de nuestro problema de empleo.

\section{3. "Los inmigrantes son más machistas que los de aquī"}

\subsection{1. ¿Qué dice nuestro trabajo?}

En nuestro estudio, este ítem ha resultado con una puntuación general de 5,36 en la escala de 1 a 10. Las puntuaciones de los alumnos de ESO son en este caso similares 
F. ETXEBERRÍA BALERDI, H. MURUA CARTÓN, ELISABET ARRIETA, J. GARMENDIA LARRAÑAGA Y J. ETXEBERRíA MURGIONDO PREJUICIOS DEL ALUMNADO DE SECUNDARIA DE GIPUZKOA ANTE LA INMIGRACIÓN

y por debajo de los niveles de Bachillerato y ciclo superior. No hemos encontrado diferencias significativas en razón del sexo y del lugar de origen de los encuestados.

\subsubsection{Otros estudios e informes}

En el estudio realizado por Ikuspegiak (2011b), se constata que el 68,9\% de las personas encuestadas en Euskadi consideran que las personas inmigrantes son más machistas que las personas nacidas en el País Vasco.

\subsubsection{La realidad de los hechos}

Según el informe del Ministerio del Interior (2008), de todas las mujeres víctimas de malos tratos en el ámbito familiar, el 67\% son españolas, y el 33\% son mujeres extranjeras. Si tenemos en cuenta que el porcentaje de mujeres extranjeras es en ese año 2007 del 11\%, constatamos una sobrerrepresentación de la población inmigrante en el capítulo de víctimas de malos tratos o violencia de género.

En la misma línea va el informe realizado por Eva López (2007), de la Federación de Mujeres Progresistas, que muestra una mayor incidencia en la población extranjera en cuanto a los datos relativos a denuncias y muertes como consecuencia de la violencia doméstica.

Carmen Vives-Cases y otras (2009) muestran, en un estudio transversal realizado a más de 10.000 mujeres que acudieron a centros de atención primaria en España (2006 y 2007), que la prevalencia de la violencia de género en las españolas es del $14,3 \%$ mientras que entre las inmigrantes es del 27,3\%.

Un informe publicado por Amnistía Internacional en 2007 indicaba que "la probabilidad de una mujer extranjera de morir asesinada a manos de su pareja o expareja superaba en cuatro veces y media a la de una española".

Finalmente, el estudio de Emakunde (2012) y citando el informe del Consejo General del Poder Judicial, referente al conjunto del Estado, titulado "Informe sobre víctimas mortales de la violencia de género y de la violencia doméstica en el ámbito de la pareja o expareja en 2010", proporciona cifras estremecedoras sobre las víctimas mortales de la violencia de género, censando en 73 las mujeres fallecidas en 2010, de las cuales 28 (38\%) eran extranjeras. Este dato destaca por la relevante sobrerrepresentación de estas mujeres, si tenemos en cuenta que la población femenina extranjera no representa más del 11,47\% del total de la población femenina en España.

\subsubsection{Discusión}

A la luz de nuestro estudio y de otros informes e investigaciones podemos concluir que el prejuicio existente sobre un mayor comportamiento machista por parte de las personas inmigrantes tiene su fundamento en la realidad. 

PREJUICIOS DEL ALUMNADO DE SECUNDARIA DE GIPUZKOA ANTE LA INMIGRACIÓN

\section{4. "Los inmigrantes nos están invadiendo"}

\subsection{1. ¿Qué dice nuestro trabajo?}

En nuestro estudio, este ítem ha resultado con una puntuación general de 5,12 en la escala de 1 a 10. Las puntuaciones de los alumnos de ESO son más elevadas que las de los alumnos de ciclos superiores, Bachillerato y ciclo superior. No hemos encontrado diferencias significativas en razón del sexo y del lugar de origen de los encuestados.

\subsubsection{Otros estudios e informes}

En el estudio realizado por Ikuspegiak (2011), se constata que las personas encuestadas en Euskadi consideran que el número de inmigrantes es mayor del que realmente existe. Hay un sobredimensionamiento en la percepción de los extranjeros, que viene reflejado por la creencia de la población autóctona de que el 17,2\% de la población es de nacionalidad extranjera. Esta percepción contrasta con el dato real de empadronamiento a 1 de enero de 2011, que sitúa el porcentaje de extranjeros en el 6,6\%. Es decir, el volumen de población extranjera percibido por la población autóctona es casi tres veces mayor al volumen real.

Según el CIs (2009), "la población española que considera que el número de inmigrantes es elevado o excesivo supone el 78,5\%, al tiempo que creen que la población extranjera residente en España es en torno al 21,26\%, cuando en realidad supone el 12\%", es decir, casi la mitad de lo que la opinión española piensa.

Podemos afirmar que, en general, la percepción de la opinión pública sobre la presencia de extranjeros está muy por encima de lo que se corresponde con la realidad.

\subsubsection{La realidad de los hechos}

En el año 2011 la población inmigrante en España es el 12,2\% y en Euskadi es el 6,6\%. Si hacemos caso a la población escolar, esas tasas son del 9,5\% en España y del 6,9\% en Euskadi (Ikuspegiak, 2011a). En realidad, Euskadi es de las comunidades autónomas que menor tasa de personas extranjeras tiene.

Se observa un cambio de tendencia a partir de los datos de los últimos años. El Instituto Nacional de Estadística (INE) nos indica que en España, en el año 2009 y 2010, hubo un incremento de 329.929 y 60.269 inmigrantes respectivamente. Se observa que la tendencia ha cambiado de sentido y en el año 2011 hubo una disminución de 17.067 personas extranjeras, pasando a 40.447 inmigrantes menos en 2012.

Por lo tanto, teniendo en cuenta los dos últimos años, podemos afirmar que la tasa de población extranjera está bajando. Por su parte, en el caso de Euskadi, la población autóctona tiende a disminuir ligeramente. 
F. ETXEBERRía BALERDI, H. MURUA CARTÓN, ELISABET ARRIETA, J. GARMENDIA LARRAÑAGA Y J. ETXEBERRÍA MURGIONDO PREJUICIOS DEL ALUMNADO DE SECUNDARIA DE GIPUZKOA ANTE LA INMIGRACIÓN

\subsubsection{Discusión}

Si atendemos a la proyección de futuro de la evolución de la población extranjera en Euskadi, podemos afirmar, sobre la base de informes como el del CES del País Vasco (2011), que "De acuerdo con esta evolución de las tasas demográficas, el número de nacimientos anuales en la CAPV pasará de 21.000 personas en 2009 a 17.600 en 2020, mientras que la cifra de defunciones crecerá de 19.400 a 21.700 . Como puede comprobarse, el crecimiento vegetativo se volverá negativo a partir de 2014”. Según este informe del Consejo Económico y Social Vasco, será la afluencia de inmigrantes la que podrá compensar ese crecimiento negativo y mantener en sus cotas equilibradas la población del País Vasco, paliando en cierta manera el envejecimiento de la población de Euskadi.

Por estas razones, el debate sobre la supuesta invasión de los inmigrantes requiere plantearse unos interrogantes concretos sobre el futuro demográfico de Euskadi y sobre la manera de contrarrestar el crecimiento negativo de la población. Los datos parecen indicar que no estamos sufriendo una invasión y que tendremos necesidad de la llegada de más inmigrantes para poder equilibrar los flujos de nacimientos y defunciones.

\section{5. "Por culpa de los inmigrantes el euskara se perderá"}

\subsection{1. ¿Qué dice nuestro trabajo?}

En nuestro estudio, este ítem ha resultado en quinto lugar con una puntuación general de 4,59 en la escala de 1 a 10. Las puntuaciones de los alumnos de ESO son más elevadas que las de los alumnos de ciclos superiores, Bachillerato y ciclo superior. Por su parte, los chicos y las chicas puntúan casi en la misma medida en esta pregunta. Si hacemos caso al país de origen, los nacidos en el País Vasco puntúan significativamente más alto que los nacidos en el extranjero.

\subsubsection{Otros estudios e informes}

En el estudio realizado por Ikuspegiak (2011b), se muestra que las personas encuestadas en Euskadi consideran mayoritariamente (60\%) que el euskara no se verá frenado por la llegada de inmigrantes, ni que se reducirá el uso del euskara en aquellas zonas del País Vasco donde actualmente es mayoritario. Frente a este dato, hay aproximadamente un 25\% de los encuestados que sí creen que la inmigración puede frenar el desarrollo del euskara y su uso. 


\subsubsection{La realidad de los hechos}

Aunque cerca de un 25\% de los ciudadanos vascos opinen que la inmigración puede frenar o dificultar el desarrollo del euskara y su uso y de que este tema se refleja también en la respuesta de los encuestados en nuestro estudio, lo cierto es que atendiendo al estudio realizado por el Gobierno Vasco (2012b) en la Comunidad Autónoma Vasca, la Comunidad Foral de Navarra y el País Vasco Norte, los datos indican todo lo contrario. En primer lugar, hay que destacar que tanto en la CAPV como en Navarra, se incrementa el número de hablantes en Euskara, aunque se estanca el uso del mismo en la vida cotidiana, y todo ello en el periodo en el que ha existido un mayor aumento de la inmigración, durante la última década. En segundo lugar, en el País Vasco Norte existe un continuo descenso en el número de vascohablantes y en el uso del euskara en la calle, precisamente en el territorio vasco en el que menos inmigración existe.

El estudio realizado por el Cluster de Sociolingüística (2012): VI. Medición del uso de las lenguas en la calle. 2011, muestra también que el uso del euskara en la calle se mantiene en el mismo nivel que hace 10 años, en términos generales. El uso del euskara se mantiene en la CAPV y Navarra y desciende en el País Vasco Norte.

\subsubsection{Discusión}

Los dos recientes estudios citados muestran que el conocimiento del euskara se está incrementando en las comunidades que más inmigración reciben, mientras que en el País Vasco Norte, en donde la inmigración es insignificante, el número de hablantes en Euskara y el uso en la vida cotidiana siguen descendiendo desde hace dos décadas.

Por lo tanto, la creencia de que por culpa de la inmigración el progreso del euskara se estancará o se frenará no tiene una justificación científica. El uso del euskara en la calle parece responder a otras pautas ajenas a una mayor o menor proporción de población inmigrante.

\section{6. "Los inmigrantes aumentan la delincuencia"}

\subsection{1. ¿Qué dice nuestro trabajo?}

En nuestro estudio, este ítem ha resultado con una puntuación media de 4,30 en la escala de 1 a 10. Las puntuaciones de las de los alumnos de ESO, de Bachillerato y de ciclo superior son muy similares, observándose un pico en el $4 .^{\circ}$ curso de ESO. No hemos encontrado diferencias significativas en razón del sexo y del lugar de origen de los encuestados. 


\subsubsection{Otros estudios e informes}

En el estudio realizado por Ikuspegiak (2011b), se constata que los encuestados de Euskadi consideran en un 46,1\% que la presencia de personas inmigrantes genera inseguridad y delincuencia. En esa misma línea, un 59,8\% de los encuestados opinan que la llegada de inmigrantes afecta negativamente a la seguridad ciudadana.

Según el CIS (2009), el 30,2\% de la población española considera que la inmigración genera más problemas de delincuencia e inseguridad.

A nivel europeo (Conseil de l'Europe, 2011a), coinciden con esta creencia el 50\% de los encuestados en el Reino Unido, el 80\% en Noruega y el 65\% en Italia. Es de tal fuerza esta idea estereotipada que "constituye probablemente el estereotipo por excelencia respecto a los inmigrantes en Europa".

Podemos afirmar que una parte importante de la opinión pública cree que la presencia de inmigrantes en nuestra sociedad genera un aumento de la inseguridad y la delincuencia.

\subsubsection{La realidad de los hechos}

Según el Ministerio del Interior del Gobierno de España (2011a), la evolución de la criminalidad en España nos muestra que en el periodo que va del año 2002 al 2010, el porcentaje de delitos y faltas por cada 1.000 habitantes desciende anualmente, pasado del $40,5 \%$ al $32,6 \%$. Es justamente ese periodo en el que más se ha incrementado la población inmigrante en España, pasando de un 4,7\% a un $12,2 \%$, o, lo que es igual, subiendo de 1.300 .000 inmigrantes a cerca de 5.000.000.

Sin embargo, constatamos a partir del Anuario Estadístico del Ministerio del Interior (2011b) que la población reclusa extranjera se ha incrementado en ese periodo, pasando del 25,9\% al 35,6\%. Respecto a la población reclusa, según el informe del Consejo de Europa (2011), en el año 2007 constituía el 45,5\% de los detenidos en Austria, el 41,2 en Bélgica, el 20,5\% en Francia, el 28\% en Alemania, el 32,9\% en Holanda, el 18,5\% en Portugal y el 30,1\% en España.

Por lo tanto, la percepción que tenemos del incremento de la delincuencia no se corresponde con los delitos reales, porque estos disminuyen cuando el crecimiento de la inmigración es muy fuerte. No obstante, es preciso tener en cuenta el incremento de la población reclusa extranjera.

\subsubsection{Discusión}

La consistencia de este prejuicio, según el cual la inmigración provoca un aumento de la delincuencia y de la inseguridad ciudadana, contrasta con los datos que elabora el Ministerio del Interior. Probablemente esta imagen negativa de la población inmigrante tiene mucho que ver con la imagen mediática que ofrecen los 
medios de comunicación, para quienes en la mayoría de los casos el tratamiento de los extranjeros suele ser desde una óptica negativa (Council of Europe, 2011b).

Por otra parte, tal y como hemos señalado, la falta de concordancia entre la disminución de los delitos y el aumento de las personas extranjeras encarceladas puede ser debida a varios factores:

- Hay que tener en cuenta que algunos de los delitos por los que se encuentran recluidos son simplemente irregularidades debidas a la falta de papeles, estancias ilegales, etc.

- Se realizan muchos más controles a las personas inmigrantes que a las personas autóctonas, tal y como el Sindicato de la Policía (sup) ha denunciado reiteradamente.

- Hay que tener en cuenta también que para las personas inmigrantes existen menos posibilidades de presunción de inocencia, libertad provisional bajo fianza, permisos de tercer grado, capacidad de defensa, abogados, etc.

- $\quad$ Por otra parte, es de considerar la afluencia de un gran número de turistas extranjeros que pueden suponer una fuente de incremento de la tasa de criminalidad. En el año 2011 fueron cerca de 57 millones de turistas los que visitaron España (Instituto de Estudios Turísticos, 2011).

- No hay que olvidar que la población extranjera en España se encuentra en la franja de edad más joven, entre 24 y 44 años, que supone en general el periodo de edad que más población reclusa acoge.

- Como se indica en el informe del Consejo de Europa (2011b), a menudo no podemos saber si las estadísticas nos dan indicaciones sobre los extranjeros o sobre el hecho de que los estereotipos guían las pesquisas de la policía.

Finalmente, hablando de la inseguridad ciudadana y desde una óptica totalmente opuesta, no podemos dejar de lado los preocupantes datos relativos al nivel de rechazo, trato desigual, discriminación, relaciones laborales ilegales, agresiones racistas, etc., que sufren las personas inmigrantes. En esta línea van los informes realizados por la Secretaría de Estado de Igualdad del Gobierno de España, en su informe anual de 2010; o el informe del Racismo y la Xenofobia en España realizado por Cea D'Ancona y Vallés Martínez (2010), y por el informe del Conseil de l'Europe (2011b) según el cual "la exposición al riesgo de violencia xenófoba y racista ha aumentado considerablemente a lo largo de los últimos años y todo ello a pesar de la débil propensión a la denuncia por parte de las víctimas y a la falta de asistencia y apoyo por parte del resto de la sociedad, incluidas las instituciones". 
F. ETXEBERRÍA BALERDI, H. MURUA CARTÓN, ELISABET ARRIETA, J. GARMENDIA LARRAÑAGA Y J. ETXEBERRÍA MURGIONDO PREJUICIOS DEL ALUMNADO DE SECUNDARIA DE GIPUZKOA ANTE LA INMIGRACIÓN

\section{REFERENCIAS BIBLIOGRÁFICAS}

AllPort, G. W. (1962) La naturaleza del prejuicio. Buenos Aires, Universitaria de Buenos Aires.

Amnistía Internacional (2007) Más riesgos y menos protección. Mujeres inmigrantes en España frente a la violencia de Género. http://www.es.amnesty.org/uploads/media/ Informe_Mas_riesgos_y_menos_proteccion_231107.pdf.

ARARTEKo-Defensor Del PueBlo (2009) Transmisión de valores a menores. Vitoria-Gasteiz, Institución del Ararteko.

- (2011) Acceso de la población inmigrante en la CAPV a los servicios y prestaciones. Vitoria-Gasteiz, Institución del Ararteko.

AYUNTAMIENTO DE BARCELONA. Estrategia para combatir rumores y estereotipos sobre diversidad cultural. http://www.bcnantirumors.cat/.

BreCKLER, S. J. (1984) Empirical validation of affect and cognition as distinct components of attitude. Journal of Personality and Social Psychology, 47, 1191-1205.

Brown, R. (1995) Prejuicio. Su Psicología Social. Madrid, Alianza Editorial.

CeA D'Ancona, M. A. y Vallés, M. S. (2010) Evolución del racismo y la xenofobia en España. Informe 2010. Madrid, Ministerio de Trabajo e Inmigración.

CIS (2009) Actitudes hacia la inmigración. Centro de Investigaciones Sociológicas. Madrid.

CONSEIL DE L'EuROPE (2011a) Guide des politiques pour le bien-être de tous dans les sociétés plurielles. Strasbourg, édition du Conseil de l'Europe. http://www.coe.int/t/dg3/socialpolicies/socialcohesiondev/source/GUIDEMIGRANTS_FR.pdf.

COUNCIL OF EUROPE (2011b) Living together. Combining diversity and freedom in $21^{\text {st }}$ Century Europe. Report of the Group of eminent persons. http://book.coe.int/EN/ficheouvrage. php?PAGEID=36ylang=ENyproduit_aliasid $=2615$.

CES. CONSEJO ECONÓMico y SOCIAL VASCo (2011) El impacto Económico y Social en la CAPV. Evolución Demográfica Prevista. Bilbo, CES.

CRUZ Roja (2012) Manual para eliminar los prejuicios contra la inmigración. Madrid, Cruz Roja Española Comunidad de Madrid. http://www.cruzrojamadrid.org/contenidos/img/ File/Empleo/Argumentario/Argumentario-\%20Frente\%20a\%20la\%20discriminacion\%20 no\%20te\%20quedes\%20sin\%20argumentos.pdf.

Dovidio, J. F. y GaerTner, S. L. (1986) Prejudice, discrimination and racism: historical trend and contemporary approaches. En Dovidio, J. F. y Gaertner, S. L. (eds.) Prejudice discrimination and racism. Nueva York, Academic Press, 1-34.

DuckitT, J. (1992) Psychology and prejudice. An historical analysis and integrative framework. American Psychologist, 47, 1182-1193.

Echebarria, J.; González, J. L.; Garaicordobil, M. T. y Villarreal, M. (eds.) (1995) Psicología Social del Prejuicio y el Racismo. Madrid, Ramón Areces.

EDEX. Los nuevos vecinos. Vitoria, Departamento de empleo y asuntos sociales. Gobierno Vasco. http://www.losnuevosvecinos.net/.

EMAKUNDE (2012) Estudio sobre las mujeres extranjeras de la sociedad vasca-2011. VitoriaGasteiz, Gobierno Vasco.

FERnÁNDEZ-CAstillo, A. y FernándeZ, J. (2006) Valoración del prejuicio racial en la infancia: adaptación preliminar de la escala de prejuicio racial sutil y manifiesto. Infancia y Aprendizaje, 29 (3), 327-342.

García, M. C.; Navas, M. S.; Cuadrado, I. y Morelo, F. (2003) Inmigración y prejuicio: actitudes de una muestra de adolescentes almerienses. Acción Psicológica, vol. 2, n. 2, 137-147. 

PREJUICIOS DEL ALUMNADO DE SECUNDARIA DE GIPUZKOA ANTE LA INMIGRACIÓN

GOBIERNO VASCO (2008) El impacto económico de la inmigración extracomunitaria en la CAPV. Vitoria-Gasteiz, Gobierno Vasco.

- (2012a) Frena el rumor. Guía práctica para combatir los rumores, los estereotipos y los prejuicios hacia la inmigración. Vitoria, Departamento de Empleo y Asuntos Sociales del Gobierno Vasco.

- (2012b) VEncuesta Sociológica. Comunidad Autónoma Vasca, Comunidad Foral de Navarra y País Vasco Norte. Vitoria, Viceconsejería de Política Lingüística. Gobierno Vasco.

Gómez, A. y Huici, C. (2001) Valores y reducción de prejuicio. En Ros, M. y Gouveia, V. V. (eds.) Psicología social de los valores humanos. Desarrollos teóricos, metodológicos y aplicados. Madrid, Biblioteca Nueva, 219-237.

Hers, R.; ReImer, J. y PaOlitTo, D. (2002) El crecimiento moral de Piaget a Kohlberg. Madrid, Narcea Ediciones.

InUSPEGIAK (2011a) Anuario de la inmigración en el País Vasco. Bilbo, Observatorio Vasco de Inmigración. http://www.ikuspegi-inmigracion.net/es/.

- (2011b) Barómetro 2011. Percepciones y actitudes hacia la inmigración extranjera. Bilbo, Observatorio Vasco de Inmigración. http://www.ikuspegi-inmigracion.net/es/.

Instituto NaCiOnal De EsTAdística (INE) Notas de prensa de los años 2009 a 2011. Madrid, Instituto Nacional de Estadística. www.ine.es/prensa/prensa.htm.

Instituto DE Estudios Turísticos (2011) Evolución de llegadas de turistas extranjeros a España. Madrid, Ministerio de Industria, Energía y turismo. http://www.iet.tourspain.es.

LEÓN, B.; RicARDO, A. y Gómez, T. (2007) Evaluación de las opiniones sobre la inmigración y la multiculturalidad en la escuela de alumnos de Magisterio. Revista Electrónica de Investigación Psicoeducativa, 12 (5), 259-282.

LóPez, E. (2007) Mujeres inmigrantes y violencia de género. Federación de Mujeres Progresistas.

MarTínez, M. C. (1996) Análisis psicosocial del prejuicio. Madrid, Ed. Síntesis.

McConahay, J. B.; Hardee, B. B. y Batss, V. (1981) Has Racism Declined in America?: It Depends upon Who Is Asking and What Is Asked. Journal of Conflict Resolution, 25, 563-579.

MINISTERIO DEL INTERIOR (2008) Evolución de la criminalidad en 2008. www.mir.es

- (2011a) Evolución de la criminalidad. Balance 2010. www.mir.es

- (2011b) Anuario Estadístico 2010. www.mir.es

Moreno, P. y Durán, A. (2002) Análisis de las actitudes prejuiciosas. Apuntes de Psicología, 20, 17-32.

Moreno Fuentes, F. J. y BRuQuetas, M. (2011) Inmigración y estado de bienestar en España. Colección Estudios Sociales, n. $\stackrel{0}{31}$. Barcelona, La Caixa.

Navas, M.; García, M. C.; Rojas, A.; Pumares, P. y Cuadrado, I. (2006) Actitudes de aculturación y prejuicio: la perspectiva de autóctonos e inmigrantes. Psicothema, vol. 18, n.. 2, 87-193.

PAjares, M. (2010) Inmigración y mercado de trabajo. Informe 2010. Observatorio Permanente de la Inmigración. Madrid, Ministerio de Trabajo e Inmigración.

Pettigrew, T. y Meertens, R. W. (1995) Subtle and blatant prejudice in Western Europe. European Journal of Social Psychology, 25, 57-75.

RED ISIR (2010) Inmigración y Salud. Escuela Andaluza de Salud Pública. Gobierno de Andalucía. http://www.redisir.net/. 
F. ETXEBERRÍA BALERDI, H. MURUA CARTÓN, ELISABET ARRIETA, J. GARMENDIA LARRAÑAGA Y J. ETXEBERRÍA MURGIONDO

PREJUICIOS DEL ALUMNADO DE SECUNDARIA DE GIPUZKOA ANTE LA INMIGRACIÓN

Retortillo, A. y Rodríguez, H. (2008) Actitudes de aculturación y prejuicio étnico en los distintos niveles educativos: un enfoque comparado. Revista Electrónica Interuniversitaria de Formación del Profesorado, 11 (2), 61-71.

Rodríguez Navarro, H. y Retortillo Osuna, A. (2006) El prejuicio en la escuela. Un estudio sobre el componente conductual del prejuicio étnico en alumnos de 5. de primaria. Revista Interuniversitaria de Formación del Profesorado: Inmigración y Escuela, 20 (2), $133-150$.

Rodríguez, R. y Rodríguez, A. (1999) Diseño de un cuestionario para la medición de las creencias sobre las diferencias raciales. Revista de Psicología Social, 14, 41-54.

RuEDA, J. F. y NAVAS, M. S. (1996) Hacia una evaluación de las nuevas formas del prejuicio racial: las actitudes sutiles del racismo. Revista de Psicología Social, 11, 131-149.

SOciolinguistika Klusterra (2012) VI. Medición del uso de las lenguas en la calle. 2011. http://www.soziolinguistika.org/files/VI\%20Kale\%20Neurketa-\%20Emaitzen\%20txostena\%20Gazteleraz.pdf.

Vives-CASES, C. y otros (2009) Violencia de género en mujeres inmigrantes españolas: magnitud, respuestas ante el problema y políticas existentes. Gaceta Sanitaria, 23, 100-106.

Wieviorka, M. (1991) El espacio del racismo. Barcelona, Paidós. 
PREJUICIOS DEL ALUMNADO DE SECUNDARIA DE GIPUZKOA ANTE LA INMIGRACIÓN

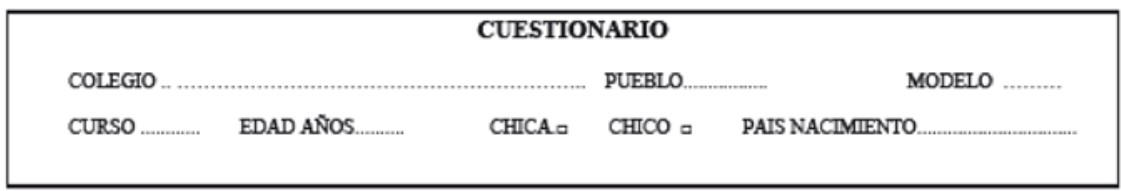

\begin{tabular}{|c|c|c|c|c|c|c|c|c|c|c|}
\hline \multirow{2}{*}{$\begin{array}{l}\text { SEGÚN TU OPINION, ¿HASTA QUE PUNTO } \\
\text { SON VERDADERAS ESTAS FRASES? }\end{array}$} & NADA & \multirow[b]{2}{*}{2} & \multirow[b]{2}{*}{3} & \multirow[b]{2}{*}{4} & \multirow[b]{2}{*}{5} & \multirow[b]{2}{*}{6} & \multirow[b]{2}{*}{7} & \multirow[b]{2}{*}{8} & \multirow[b]{2}{*}{9} & \multirow{2}{*}{$\begin{array}{l}\text { TOTAL } \\
\mathbf{1 0}\end{array}$} \\
\hline & $\mathbf{1}$ & & & & & & & & & \\
\hline \multicolumn{11}{|l|}{ 1.-Los inmigrantes nos ayudan para vivir mejor } \\
\hline \multicolumn{11}{|l|}{ 2.-Los inmigrantes nos están invadiendo } \\
\hline \multicolumn{11}{|l|}{ 3.-Las personas inmigrantes son amables } \\
\hline \multicolumn{11}{|l|}{ 4.-Reciben más ayudas que los de aquí } \\
\hline \multicolumn{11}{|l|}{ 5.-Con los inmigrantes aprendemos muchas cosas } \\
\hline \multicolumn{11}{|l|}{$\begin{array}{l}\text { 6-Por culpa de los inmigrantes el Euskara se } \\
\text { perderá }\end{array}$} \\
\hline \multicolumn{11}{|l|}{ 7.-Las personas inmigrantes son trabajadoras } \\
\hline \multicolumn{11}{|l|}{ 8.-Los inmigrantes quieren imponemos su religión } \\
\hline \multicolumn{11}{|l|}{ 9.-Deben tener los mismos derechos que los demás } \\
\hline \multicolumn{11}{|l|}{ 10.-Los inmigrantes aumentan la delincuencia } \\
\hline \multicolumn{11}{|l|}{ 11.-Las personas inmigrantes hacen las cosas bien } \\
\hline \multicolumn{11}{|l|}{ 12.-Los inmigrantes traen enfermedades a Euskadi } \\
\hline \multicolumn{11}{|l|}{$\begin{array}{l}\text { 13.-Gracias a ellos conocemos otras culturas y } \\
\text { lenguas }\end{array}$} \\
\hline \multicolumn{11}{|l|}{ 14.-Los inmigrantes quitan el trabajo a los de aquí } \\
\hline \multicolumn{11}{|l|}{ 15.-Las personas inmigrantes son gente buena } \\
\hline \multicolumn{11}{|l|}{$\begin{array}{l}\text { 16-Tienen menos formación y cultura que los de } \\
\text { aquí }\end{array}$} \\
\hline $\begin{array}{l}\text { 17.-Hacen los trabajos que la gente de aquí no } \\
\text { quiere }\end{array}$ & & & & & & & & & & \\
\hline $\begin{array}{l}\text { 18.-Los inmigrantes bajan el nivel de mestras } \\
\text { escuelas }\end{array}$ & & & & & & & & & & \\
\hline 19.-Ayudan a mejorar la economía de Euskadi & & & & & & & & & & \\
\hline $\begin{array}{l}\text { 20--Los immigrantes son más machistas que los de } \\
\text { aquí }\end{array}$ & & & & & & & & & & \\
\hline 21.-Tengo simpatia por las personas rumanas & & & & & & & & & & \\
\hline 22.-Tengo simpatia por las personas de Marruecos & & & & & & & & & & \\
\hline $\begin{array}{l}\text { 23.-Tengo simpatia por las personas de Africa } \\
\text { negra }\end{array}$ & & & & & & & & & & \\
\hline 24.-Tengo simpatia por las personas sudamericanas & & & & & & & & & & \\
\hline 25.-Tengo simpatia por las personas chinas & & & & & & & & & & \\
\hline 26--Tengo simpatia por las personas europeas & & & & & & & & & & \\
\hline 27.-Tengo simpatia por las personas .................. & & & & & & & & & & \\
\hline 28.-Tengo simpatia por las personas ................ & & & & & & & & & & \\
\hline 29.-Tengo simpatia por las personas ................. & & & & & & & & & & \\
\hline 30.-Tengo simpatia por las personas $. . . . \ldots \ldots \ldots . . . .$. & & & & & & & & & & \\
\hline & 1 & 2 & 3 & 4 & 5 & 6 & 7 & 8 & 9 & 10 \\
\hline
\end{tabular}

